\title{
Low-Abundant Cerebrospinal Fluid Proteome Alterations in Dementia with Lewy Bodies
}

\author{
Jana-Katharina Dieks $s^{\mathrm{a}, *}$, Joanna Gawinecka ${ }^{\mathrm{a}}$, Abdul R. Asif ${ }^{\mathrm{b}}$, Daniela Varges ${ }^{\mathrm{a}}$, Karin Gmitterova ${ }^{\mathrm{d}}$, \\ Jan-Hendrik Streich ${ }^{\mathrm{c}}$, Hassan Dihazic ${ }^{\mathrm{c}}$, Uta Heinemann ${ }^{\mathrm{a}}$ and Inga Zerr ${ }^{\mathrm{a}, *}$ \\ ${ }^{a}$ Department of Neurology, Clinical Dementia Center, Medical Center Georg-August University, \\ Göttingen, Germany \\ ${ }^{\mathrm{b}}$ Department of Clinical Chemistry, Medical Center Georg-August University, Göttingen, Germany \\ ${ }^{\mathrm{c}}$ Departments of Nephrology and Rheumatology, Medical Center Georg-August University, Göttingen, Germany \\ ${ }^{\mathrm{d}}$ Second Department of Neurology, Comenius University, Bratislava, Slovakia
}

\begin{abstract}
Dementia with Lewy bodies (DLB) is one of the most common neurodegenerative diseases and shares multiple clinical and neuropathological parallels with Alzheimer's (AD) and Parkinson's disease (PD). A variety of clinical signs are suggestive for the diagnosis, and imaging ( $\beta$ CIT SPECT) contributes substantially to the diagnosis. The study reported here was performed in search for a biomarker in the cerebrospinal fluid (CSF) of these patients. We applied 2D fluorescence difference gel electrophoresis and mass spectrometry to analyze the CSF proteome pattern of DLB patients after depleting twelve high-abundant proteins. The densitometric analysis of 2D gels showed the up- or down-regulation of 44 protein spots. Subsequently, 23 different proteins were identified. The majority is involved in acute phase and immune response. Many of these proteins were previously reported before as being associated with $\mathrm{AD}$ or $\mathrm{PD}$, which strongly suggests a molecular cross-talk and may explain clinical and pathological overlap of these disease entities. Among the identified proteins are two highly upregulated proteins-inter alpha trypsin inhibitor heavy chain (ITIH4) and calsyntenin 1-that may have the potential to serve as molecular biomarkers specific for DLB. The identification of DLB-associated proteome changes will help to further understand pathological processes occurring in DLB and may provide future prospects to diagnostic and therapeutic options.
\end{abstract}

Keywords: Biomarker, cerebrospinal fluid, dementia with Lewy bodies, 2-D fluorescence difference gel electrophoresis

Supplementary data available online: http://dx.doi.org/10.3233/JAD-121810

\section{INTRODUCTION}

According to various medical and scientific sources, Alzheimer's disease (AD) followed by dementia with

\footnotetext{
*Correspondence to: Inga Zerr and Jana-Katharina Dieks, Department of Neurology, Clinical Dementia Center, University Medical School, Georg-August University, Robert-Koch-Straße 40, 37075 Göttingen, Germany. Tel.: +49 551 396636; Fax: +49 551 397020; E-mails: epicjd@med.uni-goettingen.de (Inga Zerr); jana.dieks@med.uni-goettingen.de (Jana-Katharina Dieks).
}

Lewy bodies (DLB) and vascular dementia accounts for most cases of neurodegenerative dementia in the elderly [1]. Clinical diagnostic criteria have been established for all three disease entities [2-4]. Nevertheless, definite diagnosis requires the pathological examination of the brain. An antemortem non- or only minimal invasive test in easily accessible tissue or fluids like cerebrospinal fluid (CSF), blood, or urine is therefore urgently needed because the accurate and early diagnosis is important for both patients and caregivers as 
disease progression, development of symptoms, and treatment options and necessities differ significantly between the various types of dementia.

The clinical consensus guidelines define DLB as a progressive neurodegenerative disorder which is characterized by a rapid cognitive decline with co-existence of one or more of the core symptoms fluctuating attention, recurrent visual hallucinations, and spontaneous features of parkinsonism (support the diagnosis of a probable DLB) [3]. Recently, advanced imaging techniques such as $\beta$ CIT SPECT were reported to contribute substantially to the differential diagnosis [5]. At the histological level, DLB is characterized by the presence of widespread Lewy bodies and Lewy neurites which contain abnormally nitrated, phosphorylated, and ubiquitinated $\alpha$-synuclein aggregates [6]. The pathological process in the brain leads to proteome changes and, subsequently, CSF that is surrounding the diseased tissue may reflect these alterations and serve as an important instrument in clinical routine.

In this study, we analyzed the CSF proteome pattern specific for patients with DLB. Depletion of twelve high-abundant CSF proteins prior to applying 2D fluorescence difference gel electrophoresis (2D-DIGE) approach followed by mass spectrometry enabled us to determine DLB-specific pathological proteome changes in the low-abundant protein fraction, which otherwise would be out of the detection range of the chosen analytical method.

The densitometric analysis of $2 \mathrm{D}$ gels showed the up- or down-regulation of 44 protein spots and consecutively 23 different proteins could be identified. These proteins, of which the majority was involved in acute phase and immune response, were assigned to five functional groups. Interestingly, many of these differentially regulated proteins were previously found to be associated with AD or Parkinson's disease (PD).

\section{PATIENTS, MATERIAL AND METHODS}

\section{Patients}

For 2D-DIGE analysis, four CSF samples of DLB cases and four age- and gender-matched non-demented controls were used, each group consisting of two female and two male individuals. According to the consensus criteria proposed by McKeith et al. [3], DLB cases were classified as clinical probable cases (mean age $72 \pm 7$ years) and diagnostic lumbar puncture was performed at $4.7 \pm 2.3$ months after onset of disease. Individuals of the control group (CON) had a mean age of $71 \pm 7$ years and did not show any sign of cognitive decline or disease affecting the CNS. For both, DLB and control group, CSF parameters were located in normal, physiological ranges and did not show any evidence of acute or chronic inflammation and intrathecal immune response. Moreover, none of the DLB or control patients was a heavy smoker or drug- or alcohol-addict. For DLB patients, CSF-protein concentration was $395 \pm 94 \mathrm{mg} / \mathrm{l}$, lactate $1.6 \pm 0.2 \mathrm{mmol} / \mathrm{l}$, Qalb $\times 10^{3} 7.1 \pm 2.3$, and cell number $2 \pm 1 / \mu 1$. For control patients, CSFprotein concentration was $336 \pm 39 \mathrm{mg} / \mathrm{l}$, lactate $1.9 \pm 0.1 \mathrm{mmol} / \mathrm{l}, \mathrm{QAlb} \times 10^{3} 4.7 \pm 0.2$, and cell number $1 \pm 1 / \mu 1$.

To confirm differential expression of selected proteins by western blot, CSF samples from eight DLBpatients, eight patients with $\mathrm{AD}$, eight patients with $\mathrm{PD}$, and eight non-demented control patients (CON) were chosen. For DLB patients, CSF-protein concentration was $512 \pm 98 \mathrm{mg} / \mathrm{l}$, for AD patients CSF-protein concentration was $464 \pm 159 \mathrm{mg} / \mathrm{l}$, for PD patients CSF-protein concentration was $414 \pm 174 \mathrm{mg} / \mathrm{l}$, and for control patients CSF-protein concentration was $384 \pm 108 \mathrm{mg} / \mathrm{l}$. The diagnosis of $\mathrm{AD}$ and $\mathrm{PD}$ was determined according to the diagnostic criteria of the National Institute of Neurological and Communicative Disorders and Stroke and the Alzheimer's Disease and Related Disorders Association (NINCDS-ADRDA) and the National Institute of Neurological Disorders and Stroke (NINDS), respectively.

The human studies were approved by the local ethic committee (ethics proposal 36/7/02) and by an informed consent from all persons available.

\section{D fluorescence difference gel electrophoresis (2D-DIGE)}

\section{Sample preparation}

CSF samples were acquired by lumbar puncture for diagnostic purposes and stored at $-80^{\circ} \mathrm{C}$ until analysis was performed. At first, 2-4 $\mathrm{ml}$ of CSF were subjected to depletion of twelve high-abundant proteins (albumin, IgG total, IgM, IgA, transferrin, Apo A-I, Apo A-II, $\alpha 1$-Acid glycoprotein, $\alpha 2$-microglobulin, $\alpha 1$-antitrypsin, haptoglobin, and fibrinogen) using ProteomeLab IgY-12 LC2 Proteome Partitioning Kit (Beckman Coulter). The procedure was performed according to manufacturer's instruction. Using $10 \mathrm{kDa}$ Amicon filters (Millipore), sample volumes were concentrated up to around $200 \mu \mathrm{l}$ and finally protein concentration was measured using 2-D Quant Kit (Amersham Biosciences). For 1D and 2D western 
blotting, native CSF without preceding high-abundant protein depletion was used.

\section{D-DIGE and image analysis}

$20.5 \mu \mathrm{g}$ of proteins were precipitated overnight with acetone-methanol $(8: 1$; vol:vol $)$ at $-20^{\circ} \mathrm{C}$ and then centrifuged at $16000 \times g$ for $15 \mathrm{~min}$. The resulted protein pellet was resuspended in a lysis buffer containing $7 \mathrm{M}$ urea, $2.5 \mathrm{M}$ thiourea, $4 \%$ CHAPS, $30 \mathrm{mM}$ TRIS, and $5 \mathrm{mM}$ magnesium acetate and subsequently labeled with 85 pmol of CyDye (GE Healthcare) as follows: Pooled samples as internal standard with $\mathrm{Cy}$, as well as CON and DLB samples with Cy3 and Cy5. Labeling reaction was performed on ice in the dark for $30 \mathrm{~min}$, terminated by adding $10 \mathrm{mM}$ lysine and incubated for further $10 \mathrm{~min}$. Equal volumes of lysis buffer containing additional $130 \mathrm{mM}$ DTT and $0.4 \%$ 3-10 Bio-Lyte (Bio-Rad) were added to the labeling mixture. Then samples were mixed together, diluted up to $350 \mu$ l with rehydration buffer composed of $7 \mathrm{M}$ urea, 2.5 M thiourea, 4\% CHAPS, 0.2\% 3-10 Bio-Lyte, and $65 \mathrm{mM}$ DTT and loaded on ReadyStrip IPG nonlinear $\mathrm{pH} 3-10,17 \mathrm{~cm}$ strips (Bio-Rad). After $12 \mathrm{~h}$ of active rehydration at $50 \mathrm{~V}$, isoelectric focusing was initiated at $500 \mathrm{~V}$ for $1 \mathrm{~h}$, followed by ramping at $1000 \mathrm{~V}$ for $1 \mathrm{~h}$ and $5000 \mathrm{~V}$ for $2 \mathrm{~h}$. The final focusing was carried out at $8000 \mathrm{~V}$ reaching a total of $60000 \mathrm{Vh}$ (PROTEAN IEF CELL, Bio-Rad). Twice the strips were equilibrated for $20 \mathrm{~min}$ in buffer containing $6 \mathrm{M}$ urea, $2 \%$ SDS, $30 \%$ glycerin, and $150 \mathrm{mM}$ TRIS, $\mathrm{pH}$ 8.8 , supplemented with $2 \%$ DTT in the first and with $2.5 \%$ iodoacetamide in the second equilibration step. SDS-PAGE was performed overnight with homogenous $12 \%$ polyacrylamide gel using PROTEAN II XL Vertical Electrophoresis Cell (Bio-Rad). CyDyelabeled protein gels were scanned by three different lasers with band pass filtered emission wavelengths of $510 \mathrm{~nm}$ (Cy2), $575 \mathrm{~nm}$ (Cy3) and $665 \mathrm{~nm}$ (Cy5) using FLA-5100 imaging system (Fujifilm). Protein spot abundances within $12 \mathrm{CSF}$ proteome patterns (4 DLB, $4 \mathrm{CON}$, and 4 international standard) were analyzed using the Delta2D software (v. 3.4) (DECODON). Differences in spot abundance detected by densitometric analysis were statistically evaluated using unpaired Student's $t$ test. A protein spot was considered as differentially regulated when its densitometric analyses showed at least 2-fold change in abundance and when $p$-value was $<0.05$ in unpaired Student's $t$ test.

\section{Protein identification}

Gel plugs containing the proteins of interest were manually excised from silver- or Coomassie-stained gels and subjected to in-gel digestion. The detailed protocol of this procedure is given by Ramljak et al. [7]. In-gel digested peptides were chromatographically separated (C18 pepMap100 nano Series analytical column, LC Packings) and analyzed by ESI-Q-TOF Ultima Global mass spectrometer (Micromass). Data acquisition was performed using the MassLynx (v. 4.0) software and further processed on Protein- LynxGlobal-Server (v 2.1), (Micromass). The acquired data files were searched against MSDB and SwissProt databases through the Mascot search engine using a peptide mass and MS/MS fragment mass tolerance of $0.5 \mathrm{Da}$. The search criteria were set with one missed cleavage by trypsin allowed and protein modifications set to methionine oxidation and carbamidomethylcysteine when appropriate.

\section{Western blotting}

\section{$1 D$ Western blotting}

$60 \mu \mathrm{l}$ of native, non-depleted CSF samples were separated on $12 \%$ SDS-PAGE gels and transferred to PVDF membranes. The membranes were blocked with $5 \%$ skimmed milk in phosphate buffer saline with $0.2 \%$ Triton $\mathrm{X}-100$ (TBST) for $1 \mathrm{~h}$ at room temperature (RT). Subsequently, membranes were incubated overnight at $4{ }^{\circ} \mathrm{C}$ with the following primary antibodies: Rabbit anti-contactin 1 (1 : 500, Abcam), rabbit anti-chromogranin A (1: 1500, Abcam), or rabbit anti-transthyretin (1 : 40000, Abcam). Thereafter, membranes were washed with PBST and incubated for $1 \mathrm{~h}$ at RT with corresponding horseradish peroxide-conjugated secondary antibodies: Human-adsorbed anti-rabbit (1 : 7500, Santa Cruz Biotechnology) or goat anti-rabbit (1: 10000, Abcam). Immunoreactivity was detected after immersion of membranes into enhanced chemiluminescence (ECL) solution and exposition to ECL-Hyperfilm (Amersham Biosciences). Films were scanned, thereafter, densitometric and statistical analysis was performed using Image J (Image Processing and Data Analysis free software) and Sigmaplot (Exact Graphs and Data Analysis software, Systat), respectively. Proteins were considered as specifically regulated when p-value was lower than 0.05 in Kruskal-Wallis ANOVA with Tukey's range test.

\section{$2 D$ Western blotting}

Of each native, non-depleted CSF sample $150 \mu \mathrm{l}$ of proteins were precipitated overnight with acetonemethanol $(8: 1$; vol:vol $)$ at $-20^{\circ} \mathrm{C}$ and then centrifuged at $16000 \times \mathrm{g}$ for $15 \mathrm{~min}$. The pellet was then 


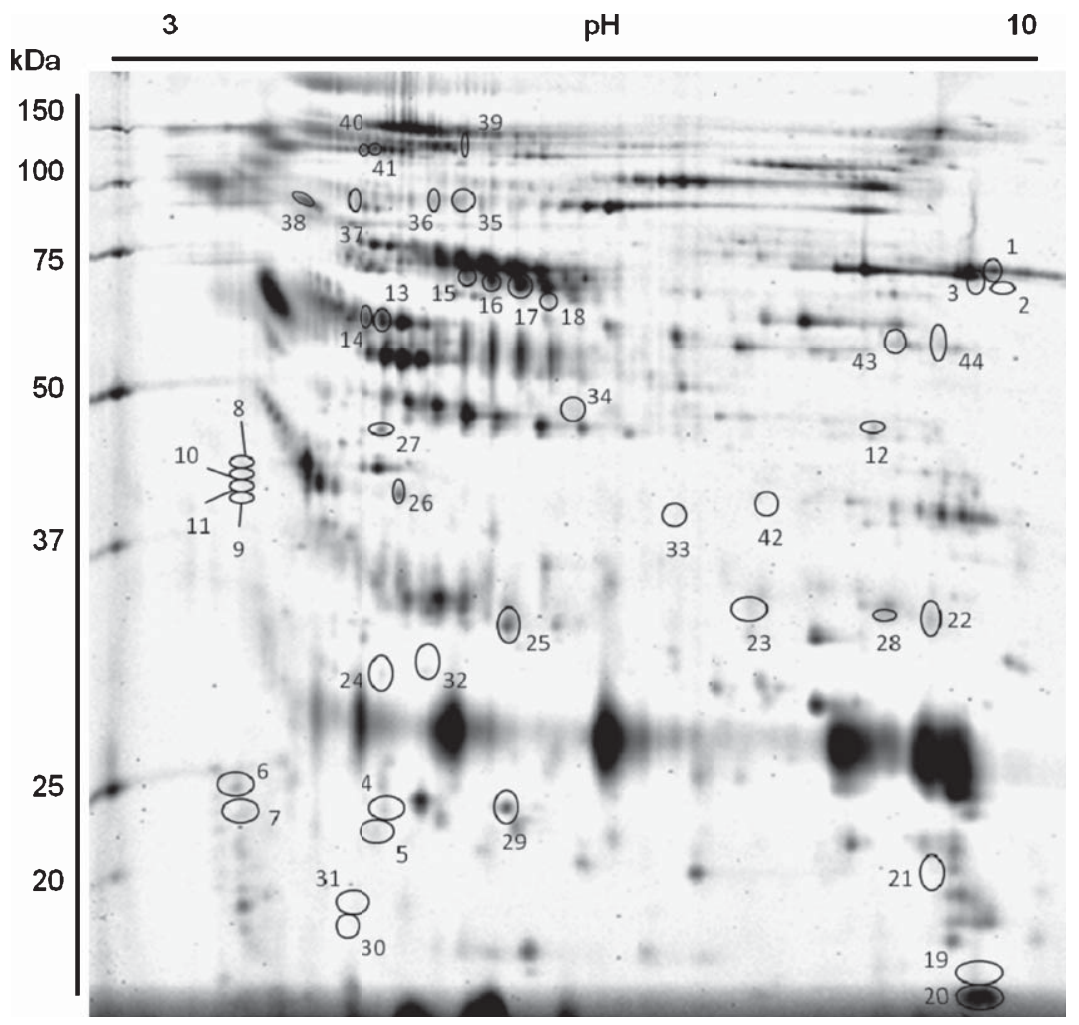

Fig. 1. Proteome map of depleted CSF from DLB patients by 2-D DIGE. The densitometric and statistical analysis of 2D maps revealed significantly different expression levels of 44 protein spots and consecutively 23 different proteins could be identified.

resuspended in a lysis buffer and loaded on a ReadyStrip IPG pH 3-10, $7 \mathrm{~cm}$ strip (Bio-Rad). After $12 \mathrm{~h}$ of active rehydration at $50 \mathrm{~V}$, isoelectric focusing was initiated at $200 \mathrm{~V}$ for $1 \mathrm{~h}$, followed by ramping at $500 \mathrm{~V}$ for $1 \mathrm{~h}$ and $1000 \mathrm{~V}$ for $1.5 \mathrm{~h}$. The final focusing was carried out at $8000 \mathrm{~V}$ reaching a total of $30000 \mathrm{Vh}$ (PROTEAN IEF CELL, Bio-Rad). Subsequent steps were performed as described above.

\section{RESULTS}

\section{General observations}

Using Delta 2D's 100\% spot matching approach, we detected a total amount of 1,978 protein spots on the $2 \mathrm{D}$ proteome patterns of the low-abundant protein fraction from CSF of DLB patients. Densitometric and statistical analysis revealed that 44 protein spots $(2.2 \%$ of all protein spots) showed differential expression in DLB (Fig. 1). Of these, 37 protein spots were identified by mass spectrometry, corresponding to 23 different proteins. Discrepancy between number of protein spots and proteins can be explained by the coexistence of different isoforms of the same proteins which vary in their isoelectric point and/or molecular weight. For the remaining seven protein spots, identification was not accomplishable due to very faint signal on silver- or colloidal Coomassie stained preparative gels. Moreover, protein spots 40 and 41 were identified as ITIH4 or calsyntenin 1; due to almost identical molecular weight and isoelectric point (pI), conclusive protein identification was not possible.

Of the 23 identified proteins, 20 were upregulated and two were down-regulated. Interestingly, for one protein one isoform showed an increased level while the second one showed a decreased level (Table 1).

Identified proteins were assigned to five different groups according to their biological functions using two independent sources for classification (IPA, Ingenuity Systems, trial version) web-based software application and UniProt protein database: Acute phase reactants (APRS)/immune response, glucose metabolism, lipid metabolism, cell structure and adhesion, and signal transduction (Fig. 2). Four proteins could not be allocated to these groups and were subsumed under "other function". Major alteration in the low-abundant CSF proteome fraction of DLB patients 
Table 1

List of DLB-related proteins in CSF. A protein spot was considered as DLB-regulated when its densitometric analyses showed at least 2-fold of change in abundance and when $p$-value was $<0.05$ in unpaired Student's $t$ test. \# indicates two proteins, which due to very similar molecular weight, isoelectric point ( $\mathrm{pI}$ ), and Mascot score could not be ultimately differentiated from each other

\begin{tabular}{|c|c|c|c|c|c|c|c|c|c|}
\hline $\mathrm{D}$ & Protein name & $\begin{array}{l}\text { Fold of } \\
\text { change }\end{array}$ & & $p$-value & $\begin{array}{c}\text { UniProt } \\
\text { accession }\end{array}$ & MW (kDa) & $\mathrm{pI}$ & Score & $\begin{array}{l}\text { Queries } \\
\text { matched }\end{array}$ \\
\hline $40 \mathrm{a}$ & $\begin{array}{l}\text { Inter-alpha-trypsin inhibitor heavy } \\
\text { chain H4 (ITIH4) }\end{array}$ & 87,9 & $\uparrow$ & 0.025 & Q14624 & 103 & 6,5 & 580 & 18 \\
\hline $41 \mathrm{a}$ & & 60,1 & $\uparrow$ & 0.034 & & & & & \\
\hline $40 \mathrm{~b}$ & Calsyntenin $1(\mathrm{CSTN} 1)^{\#}$ & 87,9 & $\uparrow$ & 0.025 & P094985 & 110 & 4,8 & 328 & 8 \\
\hline $41 b$ & & 60,1 & $\uparrow$ & 0.034 & & & & & \\
\hline 1 & Complement C4a (COA4) & 6,6 & $\uparrow$ & 0.020 & P0C0L4 & 193 & 6,7 & 867 & 22 \\
\hline 39 & Complement C3 (CO3) & 6,1 & $\uparrow$ & 0.042 & P01024 & 187 & 6 & 428 & 20 \\
\hline 11 & Chromogranin A (CGA) & 4,9 & $\uparrow$ & 0.009 & P10645 & 51 & 4,6 & 171 & 6 \\
\hline 10 & & 3,4 & $\uparrow$ & 0.028 & & & & & \\
\hline 9 & & 3,1 & $\uparrow$ & 0.026 & & & & & \\
\hline 8 & & 3 & $\uparrow$ & 0.018 & & & & & \\
\hline 7 & & 3,8 & $\uparrow$ & 0.003 & & & & 110 & 3 \\
\hline 6 & & 2,1 & $\uparrow$ & 0.029 & & & & & \\
\hline 24 & Prostaglandin- $\mathrm{H} 2$ & 4,9 & $\uparrow$ & 0.004 & P41222 & 21 & 7,7 & 77 & 2 \\
\hline 21 & D-isomerase (PDGDS) & 2,5 & $\uparrow$ & 0.020 & & & & 97 & 2 \\
\hline 22 & & 2,2 & $\uparrow$ & 0.008 & & & & 166 & 3 \\
\hline 23 & & 2,1 & $\uparrow$ & 0.029 & & & & 156 & 4 \\
\hline 29 & Glutathione peroxidase 3 (GPX3) & 4,4 & $\uparrow$ & 0.027 & P22352 & 26 & 8,3 & 112 & 3 \\
\hline 37 & Prothrombin (THRB) & 4,1 & $\uparrow$ & 0.027 & P00734 & 70 & 5,6 & 643 & 20 \\
\hline 36 & Contactin 1 (CNTN1) & 3,6 & $\uparrow$ & 0.002 & Q12860 & 113 & 5,6 & 179 & 6 \\
\hline 25 & Transthyretin (TTHY) & 3,3 & $\uparrow$ & 0.012 & P02766 & 16 & 5,5 & 498 & 7 \\
\hline 12 & $\alpha$-enolase (ENOA) & 3,1 & $\uparrow$ & 0.001 & P06733 & 77 & 7 & 143 & 5 \\
\hline 26 & $\begin{array}{l}\text { Apolipoprotein A-IV precursor } \\
\text { (APOA4) }\end{array}$ & 3 & $\uparrow$ & 0.017 & P06727 & 45 & 5,3 & 53 & 2 \\
\hline 42 & $\begin{array}{l}\text { Fructose-bisphosphate aldolase C } \\
\text { (ALDOC) }\end{array}$ & 2,7 & $\uparrow$ & 0.043 & P09972 & 39 & 6,4 & 60 & 3 \\
\hline 28 & $\begin{array}{l}\text { Insulin-like growth factor-binding } \\
\text { protein } 2 \text { (IGFBP2) }\end{array}$ & 2,5 & $\uparrow$ & 0.041 & P18065 & 35 & 7,5 & 325 & 6 \\
\hline 38 & Amyloid-like protein 1 (APLP1) & 2,4 & $\uparrow$ & 0.005 & P51693 & 72 & 5,5 & 301 & 14 \\
\hline 35 & Gelsolin (GELS) & 2,3 & $\uparrow$ & 0.011 & P06396 & 86 & 5,9 & 87 & 4 \\
\hline 43 & $\begin{array}{l}\text { Pyruvate kinase isozymes M1/M2 } \\
\text { (KPYM) }\end{array}$ & 2,2 & $\uparrow$ & 0.047 & P14618 & 58 & 8 & 556 & 17 \\
\hline 5 & Ganglioside GM2 activator (SAP3) & 2,1 & $\uparrow$ & 0.025 & P17900 & 21 & 5,2 & 69 & 2 \\
\hline 4 & & 2 & $\uparrow$ & 0.001 & & & & 44 & 1 \\
\hline 27 & $\begin{array}{l}\text { Pigment epithelium-derived factor } \\
\text { precursor (PEDF) }\end{array}$ & 2,1 & $\uparrow$ & 0.024 & P36955 & 47 & 6,8 & 464 & 11 \\
\hline 34 & $\begin{array}{l}\mathrm{N} \text {-acetyllactosaminide beta-1,3-N- } \\
\text { acetylglucosaminyl-transferase } \\
\text { (B3GN1) }\end{array}$ & 2 & $\uparrow$ & 0.039 & Q43505 & 47 & 6,8 & 182 & 6 \\
\hline 18 & Serum albumin (ALBU) & 0.43 & $\downarrow$ & 0.006 & $\mathrm{P} 02768$ & 69 & 5,9 & 429 & 14 \\
\hline 15 & & 0,45 & $\downarrow$ & 0.007 & & & & 1081 & 31 \\
\hline 16 & & 0,46 & $\downarrow$ & 0.003 & & & & 1037 & 25 \\
\hline 17 & & 0,5 & $\downarrow$ & 0.005 & & & & 812 & 20 \\
\hline 13 & Angiotensinogen (ANGT) & 0,44 & $\downarrow$ & 0.002 & P01019 & 53 & 5,9 & 96 & 3 \\
\hline 14 & & 0,5 & $\downarrow$ & 0.004 & & & & & \\
\hline 20 & Cystatin C (CYTC) & 2,6 & $\uparrow$ & 0.012 & P01034 & 16 & 9 & 227 & 3 \\
\hline 19 & & 0,27 & $\downarrow$ & 0.025 & & & & & \\
\hline
\end{tabular}

was observed in proteins involved in APRS/immune response.

\section{Proteins involved in APRS/immune response}

15 protein spots on 2D map corresponding to different isoforms of eight proteins were involved in APRS/immune response. Most of them act as direct or indirect activators of the complement system. Among them, complement $\mathrm{C} 3$, complement $\mathrm{C} 4 \mathrm{a}$, transthyretin, pigment epithelium-derived factor, and prothrombin were 2- to 7-fold upregulated, while ITIH4 showed the highest 60- to 88-fold upregulation. In contrast, angiotensinogen and albumin were around 2-fold down-regulated. 


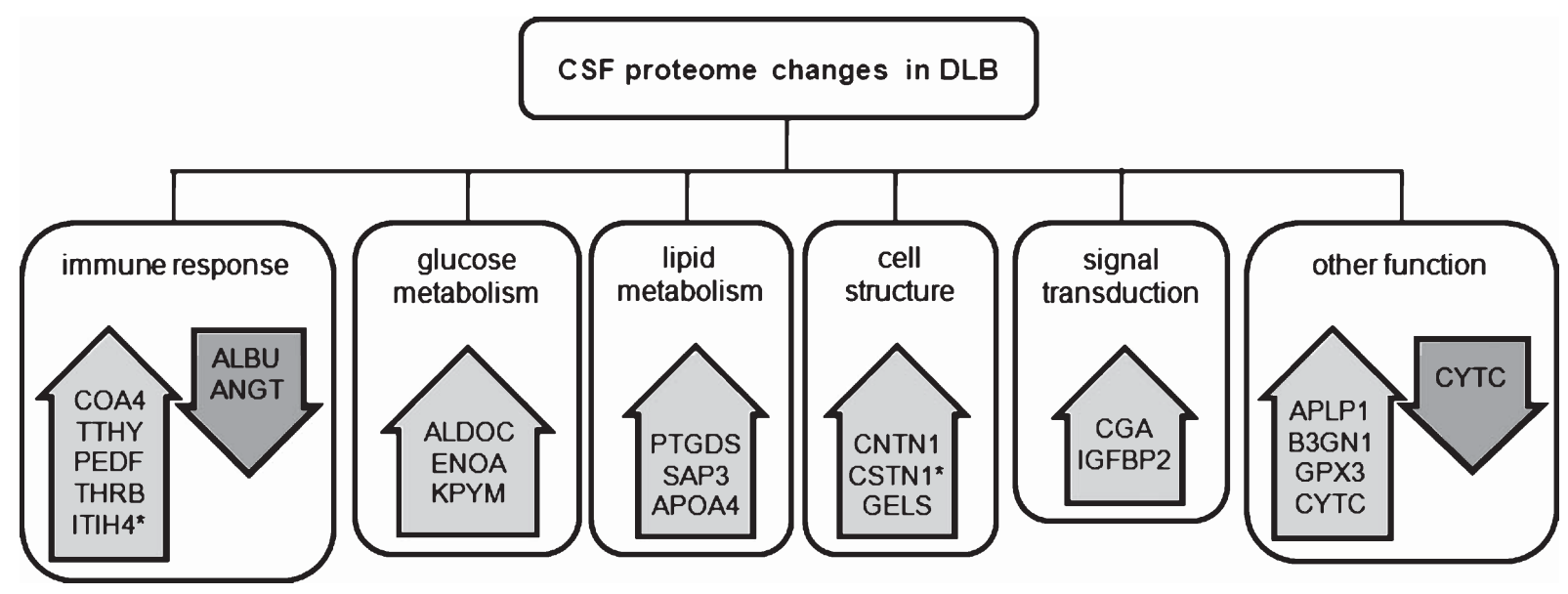

Fig. 2. The biological functions of DLB-associated proteins in CSF. The major alteration in CSF proteome was observed within the group of proteins involved in immune response. The remaining proteins were attributed to the following functional groups: glucose metabolism, lipid metabolism, signal transduction, and cell structure. Proteins that did not relate to any of those groups were subsumed in the group "others". *indicates two proteins, which due to very similar molecular weight, pI, and Mascot score could not be ultimately differentiated from each other.

\section{Proteins associated with glucose metabolism}

Three enzymes (fructose-bisphosphate aldolase C, pyruvate kinase isozymes M1/M2, and $\alpha$-enolase) catalyzing important metabolic processes were 2 - to 3-fold upregulated.

\section{Proteins involved in lipid metabolism}

Similarly, all three proteins involved in lipid metabolism displayed elevated levels in DLB. Four isoforms of prostaglandin-H2 D-isomerase were 2- to 5-fold upregulated. Two isoforms of ganglioside GM2 activator and apolipoprotein A-IV showed 2- and 3fold upregulation, respectively.

\section{Proteins involved in cell structure and adhesion}

Contactin 1 and gelsolin, both associated with cell adhesion and cytoskeleton, were significantly 2- to 3fold upregulated. Calsyntenin 1 shared the highest 60 to 88-fold upregulation with ITIH4.

\section{Proteins involved in signal transduction}

Chromogranin A isoforms displayed 2- to 5-fold increase in concentration while insulin-like growth factor-binding protein 2 showed 2.5-fold upregulation.

\section{Other differentially regulated proteins in $D L B$}

The remaining proteins (amyloid-like protein 1, Nacetyllactosaminide beta-1,3-N-acetylglucosaminyltransferase (B3GN1), glutathione peroxidase 3, and cystatin C) were not classified as belonging to one of the above mentioned functional groups. Amyloid-like protein 1 and B3GN1 were around 2-fold upregulated while glutathione peroxidase 3 more than 4 -fold. Cystatin $\mathrm{C}$, an important inhibitor of cysteine proteinases, was corresponding to two oppositely regulated protein spots (ID 19 : 2.6-fold upregulated, ID 20 : 3.8-fold down-regulated) with slightly different molecular weight. It is likely that in DLB cystatin C either undergoes some modification resulting in the observed molecular weight shift or that the two isoforms are modulated in an opposite manner.

\section{Verification of 2D-DIGE experiments}

Further, we focused our interest on three particular proteins belonging to different functional groups and performed $2 \mathrm{D}$ and $1 \mathrm{D}$ western blot analysis in order to validate our findings from 2D-DIGE experiments. Analysis was performed for transthyretin, contactin 1, and chromogranin A. Representative 2D western blots were performed in order to reinforce 2D-DIGE results and to support following 1D western blot analysis (Fig. 3). Using 1D immunoblots, protein levels in CSF were compared between DLB, AD, and PD patients as well as non-demented control patients. Each group consisted of eight individuals (Fig. 4).

Transthyretin immunoblot analysis revealed the presence of two bands corresponding to transthyretin dimers and monomers. The monomeric form was 1.6fold upregulated in DLB in comparison to CON. No further significant change in protein abundance was detected for neither monomers nor dimers. Interestingly, dimer western blot map showed a double band 
A
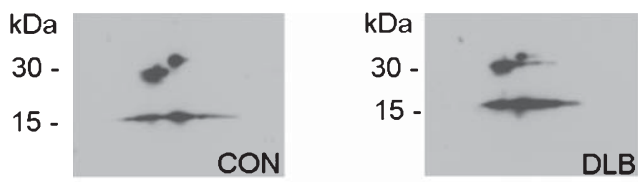

B
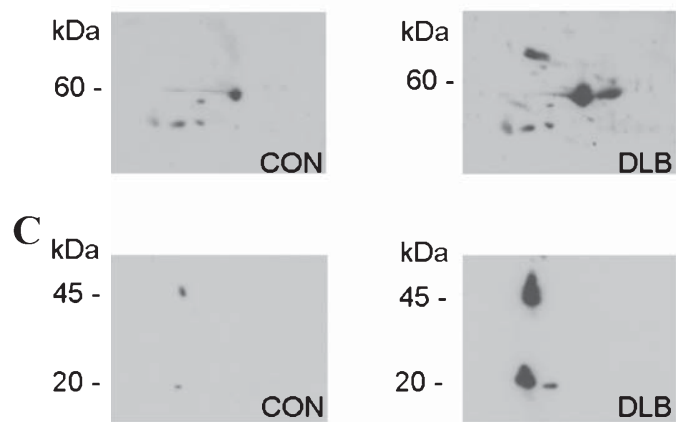

Fig. 3. Representative 2D western blots of transthyretin, contactin 1, and chromogranin A. Representative 2D western blots of transthyretin (A), contactin 1 (B), and chromogranin A (C) were performed in order to reinforce 2D-DIGE results and to support following 1D western blot analysis. Each pair of CON and DLB patients was analyzed independently.

in three out of eight PD patients but in no other group (Fig. 4A).

A significant increase in contactin 1 level was found in DLB compared to all other groups. The highest 3.4fold of change was computed between DLB and PD while the lowest 2-fold of change was between DLB and AD. Finally, almost 3-fold of change was found between DLB and CON (Fig. 4B).

Furthermore, two bands were analyzed from chromogranin A immunoblot. The upper band at around $45 \mathrm{kDa}$ corresponds to the native chromogranin A molecule and the lower one at $20 \mathrm{kDA}$ is possibly a truncated form. No significant difference between DLB and CON was detected either for the upper or for the lower band of chromogranin A. However, two chromogranin A forms were 2- to 3-fold upregulated in PD in comparison to DLB. The native form was also 2.6-fold upregulated in AD compared to DLB (Fig. 4C).

\section{DISCUSSION}

DLB is a progressive and disabling neurodegenerative disease, the second most common after AD [8]. Due to the overlap of clinical signs and symptoms with $\mathrm{AD}$ or PD, DLB is often diagnosed late or even misdiagnosed [9].

At histological level, DLB is characterized by the presence of Lewy bodies and Lewy neurites mainly formed of abnormally modified and aggregated $\alpha$-synuclein as a part of a complex pathology leading to proteome changes in the CNS tissue $[3,6]$. Subsequently, CSF as the unique body fluid surrounding the diseased brain may reflect these alterations. Yet in our study, proteins characteristic for common features of the DLB pathology such as $\alpha$-synuclein, and other components of Lewy bodies such as crystalline, ubiquitin, and enzymes of the ubiquitin cycle, tau, amyloid- $\beta$, or synaptophysin were not found to be specifically regulated in CSF. Rather we found various CSF proteins to be regulated that are known to be involved in biological functions known to be related to a multitude of neurodegenerative processes. Although overlap is usually high, proteins found to be important in the diseased brain tissue must not necessarily be found in CSF.

However, CSF analysis is challenging in terms of a high dynamic range of protein concentrations. Particular proteins such as albumin or immunoglobulins are dominant in CSF and conceal many low-abundant proteins so these remain undetected when analyzed by conventional techniques such as $2 \mathrm{D}$ gel electrophoresis and mass spectrometry. Therefore, to achieve a more effective coverage of low-abundance proteins, the immunodepletion of twelve of the highest-abundant CSF proteins was performed. Nevertheless, albumin, which belongs to the twelve proteins undergoing depletion, was found as down-regulated in DLB. According to manufacturer's instructions, the partitioning efficiency of the used kit differs for the various depleted proteins from 90 to $>99.5 \%$. Albumin is the most 

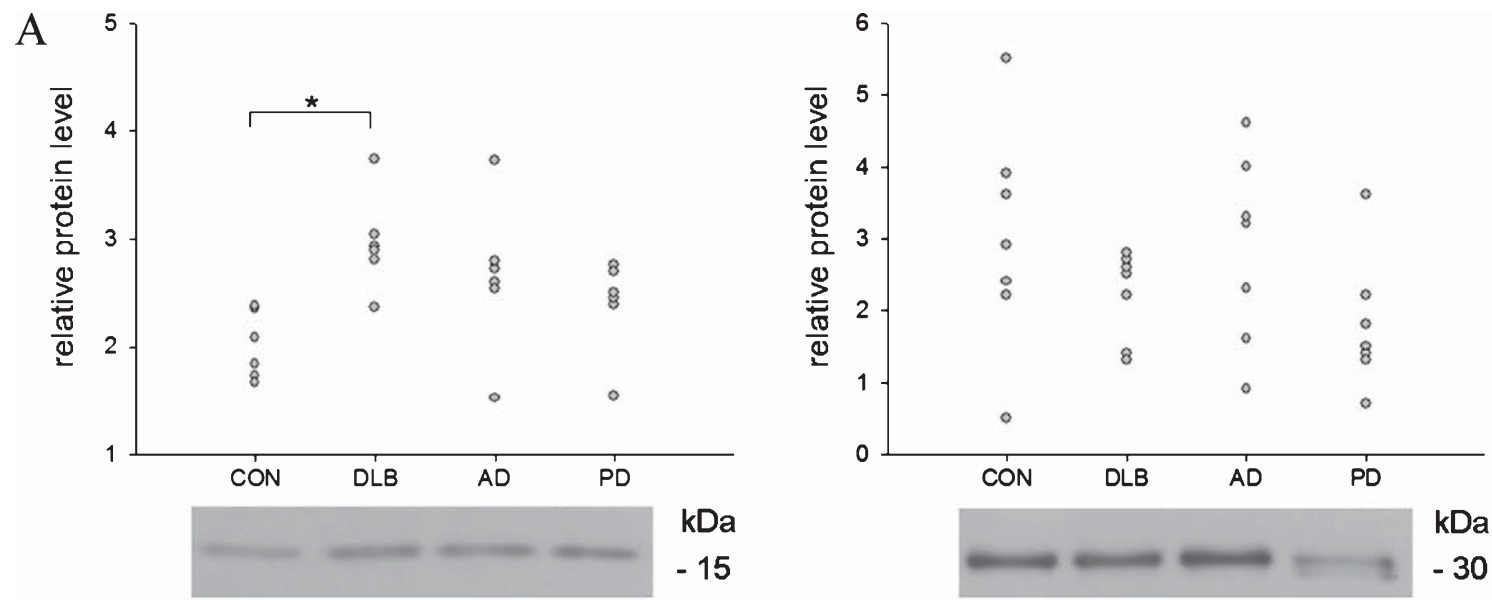

B
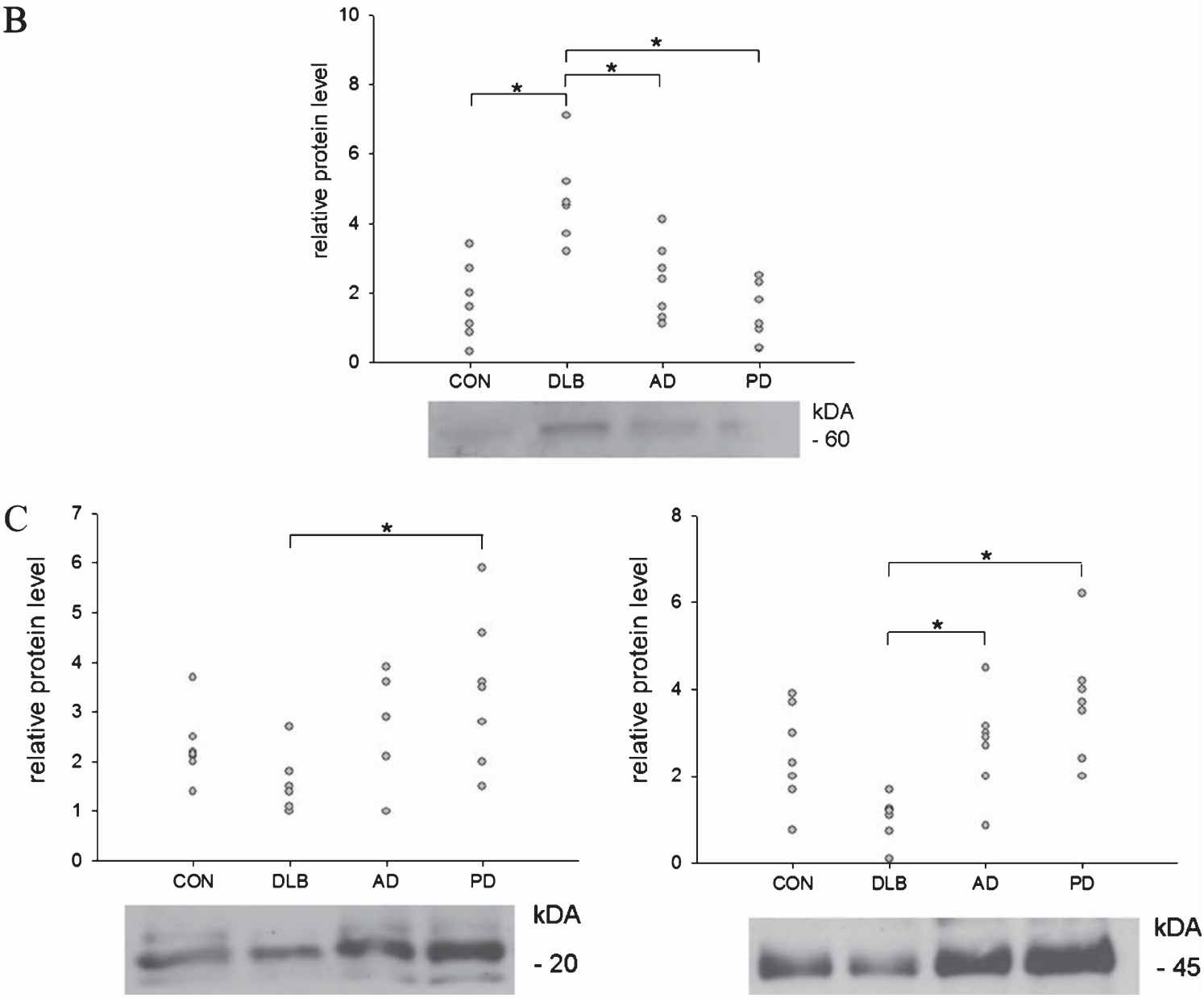

Fig. 4. Relative levels of transthyretin, contactin 1, and chromogranin A. The DLB-related regulation of of transthyretin (A), contactin 1 (B), and chromogranin $\mathrm{A}(\mathrm{C})$ was analyzed in a larger group of DLB, CON, AD, and PD patients. In brief, the monomeric form of transthyretin was 1.6-fold upregulated in DLB compared to CON, but no further significant change in protein abundance was detected, neither for monomers nor for dimers. A significant 2- to 3-fold increase in contactin 1-level was found in DLB in comparison to all other groups. No significant difference between DLB and CON was detected, neither for the upper nor for the lower band of chromogranin A. However, two chromogranin A forms were upregulated in PD compared to DLB. The native form was also upregulated in AD in comparison to DLB. The representative blots are shown below graphs. ${ }^{*} p<0.05$ in Kruskal-Wallis ANOVA test. 
abundant protein in human CSF and its upper normal range in adults is $0.5 \mathrm{mg} / \mathrm{ml}$. Therefore, its concentration even after depletion was still sufficient to detect it on 2D CyDye-labeled gel (detection limit is around $0.25 \mathrm{ng}$ of protein). The densitometric and statistical analysis of CSF 2D maps revealed the differential expression of 23 distinct proteins. Western blot analysis of three proteins (transthyretin, contactin 1, and chromogranin A) was performed and mostly confirmed our findings on 2D maps. Contactin 1 even showed a promising significant differentiation not only between DLB and healthy control patients but also AD and PD which might be helpful in terms of diagnostic potential. Results for regulation of chromogranin A obtained by 2D gels could not be confirmed in classic western blot analysis. One possible explanation for this may be the different technical properties of 2D gel electrophoresis versus western blot analysis. Also, CSF was subjected to depletion of twelve high-abundant proteins prior to applying 2D gel electrophoresis. For western blots, native CSF samples were used. Therefore interferences of high-abundant proteins are possible.

Neuroinflammation is a critical component in progression of many neurodegenerative diseases, including DLB, as has been demonstrated. It has been previously shown that aggregated $\alpha$-synuclein activates microglia and astrocytes inducing neuroinflammatory response [10]. Another immunochemical study revealed classical complement pathway activators like $\mathrm{C} 3$ and $\mathrm{C} 4$ in degenerating Lewy body-bearing neurons and extracellular Lewy bodies as potential inductors of immune response and microglial activation [11]. Complement activation also occurs around Lewy bodies and melanized neurons in the substantia nigra of PD-affected brain [12]. Moreover, expression levels of acute phase proteins are strongly regulated by inflammatory mediators. Taken together, these data are in accordance with our findings on major alteration in CSF proteome of DLB patients for proteins involved in immune response.

Disturbed insulin signaling, glucose hypometabolism, and deficient energy metabolism were hypothesized to contribute to neurodegeneration in $\mathrm{AD}$ (reviewed in [13]). All three glucose metabolismrelated enzymes, which we found in our study on DLB, were already mentioned in context of oxidative stress and neurodegenerative processes. For instance, aldolase $\mathrm{C}$ and $\alpha$-enolase expression levels were increased in AD-affected hippocampus [14] and their expression levels or of oxidative damage were modulated by antioxidant-enriched diet and behavioral enrichment in the canine model of human aging [15].
Modifications of lipid metabolism pathways, lipid rafts, or even proteins involved in lipid metabolism are also known to be associated with neurodegenerative diseases. $\alpha$-synuclein can bind and interact with lipids and phospholipids or gangliosides and lipid rafts mediate its synaptic localization [16, 17]. Therefore, it is likely that abnormally modified and aggregated $\alpha$-synuclein disturbs lipid metabolism and changes cellular localization negatively influencing synaptic functioning.

As in other neurodegenerative diseases, gelsolin, an actin-filament regulator, might play some important role in DLB pathogenesis or contribute to $\alpha$-synuclein aggregation processes. Indeed, it has been shown that gelsolin co-occurred with $\alpha$-synuclein in Lewy bodies in the human brain and with Lewy body-like inclusions in $\alpha$-synuclein overexpressing cells. In vitro, gelsolin can also enhance aggregation of $\alpha$-synuclein [18].

Increasing evidence indicates that different misfolding proteins engage common molecular and cellular pathways in pathogenic processes occurring in various neurodegenerative diseases. Furthermore, interaction between $\alpha$-synuclein, tau, and amyloid- $\beta$, as well as the fact that one misfolding protein can promote accumulation of another one, may be the key component to linking the pathologies of $\mathrm{AD}, \mathrm{PD}$, and DLB $[19,20]$. These common molecular mechanisms might be reflected in overlapping proteomic changes in the CSF making conclusive differential diagnosis using a biomarker a challenging task. Many proteins differentially regulated in DLB identified in this study have been found to be regulated in $\mathrm{CSF}$ of $\mathrm{AD}$ or $\mathrm{PD}$ patients. The most frequent reported proteins in both diseases are chromogranin A, cystatin C, prostaglandin-H2 D-isomerase, pigment epithelium-derived factor, and gelsolin [21-24]. In our study, ITIH4 and calsyntenin 1 were identified as the highest regulated in DLB. The potential for both proteins become a CSF biomarker for DLB requires further technical development toward an easy applicable and widely available detection system. Interestingly, among various other proteins ITIH4 was already proposed a candidate CSF biomarker that may reflect AD-related pathophysiologic changes [22]. In the same proteomic study, calsyntenin 1 was also reported to be down-regulated in CSF of AD patients [22]; in contrast calsyntenin 1 was found to be upregulated in CSF of PD patients [24]. Further analysis of both these proteins regarding abundances in CSF of patients of all disease entities analyzed in this study seems adequate and promising of relevant findings. 
In summary, depletion of twelve high abundant proteins enabled us to have deeper insight in DLB-associated proteome changes in CSF. The identification of DLB-associated protein changes will help to further understand pathological processes occurring in DLB and may provide future prospects to diagnostic and therapeutic options. Novel CSF biomarkers highly specific for DLB would be substantial when facing difficulties in distinguishing between DLB from AD and PD, which show multiple parallels in clinicopathological presentation.

\section{SUPPORTING INFORMATION}

One supplementary file (available online: http://www.j-alz.com/issues/34/vol34-2.html\#supplementarydata03) contains MS data including MS/MS spectra for proteins identified from 3 or less peptides.

\section{ACKNOWLEDGMENTS}

This study is supported by grants from Bundesministerium für Bildung und Forschung within the German Network for Degenerative Dementia (KNDD-2, 20122015, determinants for disease progression in AD, grant No. 01GI1010C), within the framework of the Joint Programme Neurodegenerative Disease research - JPND - Biomarker based diagnosis in rapid progressive dementia, 01ED1201A and Verein zur Förderung der Forschung an der Neurologischen Klinik e.V.

Authors thank Barbara Ciesielczyk, Christa Scholz, and Christina Wiese for their outstanding technical help and valuable advice.

Authors' disclosures available online (http://www.jalz.com/disclosures/view.php?id=1567).

\section{REFERENCES}

[1] Holmes C, Cairns N, Lantos P, Mann A (1999) Validity of current clinical criteria for Alzheimer's disease, vascular dementia and dementia with Lewy bodies. Br J Psychiatry 174, 45-50.

[2] McKhann G, Drachman D, Folstein M, Katzman R, Price D, Stadlan EM (1984) Clinical diagnosis of Alzheimer's disease: Report of the NINCDS-ADRDA Work Group under the auspices of Department of Health and Human Services Task Force on Alzheimer's Disease. Neurology 34, 939-944.

[3] McKeith IG, Galasko D, Kosaka K, Perry EK, Dickson DW, Hansen LA, Salmon DP, Lowe J, Mirra SS, Byrne EJ, Lennox G, Quinn NP, Edwardson JA, Ince PG, Bergeron C, Burns A, Miller BL, Lovestone S, Collerton D, Jansen EN, Ballard C, de Vos RA, Wilcock GK, Jellinger KA, Perry RH (1996) Consensus guidelines for the clinical and pathologic diagnosis of dementia with Lewy bodies (DLB): Report of the consortium on DLB international workshop. Neurology 47, 1113-1124.
[4] Roman GC, Tatemichi TK, Erkinjuntti T, Cummings JL, Masdeu JC, Garcia JH, Amaducci L, Orgogozo JM, Brun A, Hofman A, et al. (1993) Vascular dementia: Diagnostic criteria for research studies Report of the NINDS-AIREN International Workshop. Neurology 43, 250-260.

[5] McKeith I, O'Brien J, Walker Z, Tatsch K, Booij J, Darcourt J, Padovani A, Giubbini R, Bonuccelli U, Volterrani D, Holmes C, Kemp P, Tabet N, Meyer I, Reininger C (2007) Sensitivity and specificity of dopamine transporter imaging with 123IFP-CIT SPECT in dementia with Lewy bodies: A phase III, multicentre study. Lancet Neurol 6, 305-313.

[6] Baba M, Nakajo S, Tu PH, Tomita T, Nakaya K, Lee VM, Trojanowski JQ, Iwatsubo T (1998) Aggregation of alphasynuclein in Lewy bodies of sporadic Parkinson's disease and dementia with Lewy bodies. Am J Pathol 152, 879884.

[7] Ramljak S, Asif AR, Armstrong VW, Wrede A, Groschup MH, Buschmann A, Schulz-Schaeffer W, Zerr I (2008) Physiological role of the cellular prion protein $(\mathrm{PrPc})$ : Protein profiling study in two cell culture systems. J Proteome Res 7 , 2681-2695.

[8] Aarsland D, Rongve A, Nore SP, Skogseth R, Skulstad S, Ehrt U, Hoprekstad D, Ballard C (2008) Frequency and case identification of dementia with Lewy bodies using the revised consensus criteria. Dement Geriatr Cogn Disord 26, 445452.

[9] Noe E, Marder K, Bell KL, Jacobs DM, Manly JJ, Stern Y (2004) Comparison of dementia with Lewy bodies to Alzheimer's disease and Parkinson's disease with dementia. Mov Disord 19, 60-67.

[10] Lee HJ, Kim C, Lee SJ (2010) Alpha-synuclein stimulation of astrocytes: Potential role for neuroinflammation and neuroprotection. Oxid Med Cell Longev 3, 283-287.

[11] Iseki E, Marui W, Sawada H, Ueda K, Kosaka K (2000) Accumulation of human alpha-synuclein in different cytoskeletons in Lewy bodies in brains of dementia with Lewy bodies. Neurosci Lett 290, 41-44.

[12] Loeffler DA, Camp DM, Conant SB (2006) Complement activation in the Parkinson's disease substantia nigra: An immunocytochemical study. J Neuroinflammation 3, 29.

[13] Rhein V, Eckert A (2007) Effects of Alzheimer's amyloid-beta and tau protein on mitochondrial function - role of glucose metabolism and insulin signalling. Arch Physiol Biochem 113, 131-141.

[14] Sultana R, Boyd-Kimball D, Cai J, Pierce WM, Klein JB, Merchant M, Butterfield DA (2007) Proteomics analysis of the Alzheimer's disease hippocampal proteome. J Alzheimers Dis 11, 153-164.

[15] Opii WO, Joshi G, Head E, Milgram NW, Muggenburg BA, Klein JB, Pierce WM, Cotman CW, Butterfield DA (2008) Proteomic identification of brain proteins in the canine model of human aging following a long-term treatment with antioxidants and a program of behavioral enrichment: Relevance to Alzheimer's disease. Neurobiol Aging 29, 51-70.

[16] Fortin DL, Troyer MD, Nakamura K, Kubo S, Anthony MD, Edwards RH (2004) Lipid rafts mediate the synaptic localization of alpha-synuclein. $J$ Neurosci 24, 6715-6723.

[17] Martinez Z, Zhu M, Han S, Fink AL (2007) GM1 specifically interacts with alpha-synuclein and inhibits fibrillation. Biochemistry 46, 1868-1877.

[18] Welander H, Bontha SV, Nasstrom T, Karlsson M, Nikolajeff F, Danzer K, Kostka M, Kalimo H, Lannfelt L, Ingelsson M, Bergstrom J (2011) Gelsolin co-occurs with Lewy bodies in vivo and accelerates alpha-synuclein aggregation in vitro. Biochem Biophys Res Commun 412, 32-38. 
[19] Obi K, Akiyama H, Kondo H, Shimomura Y, Hasegawa M, Iwatsubo T, Mizuno Y, Mochizuki H (2008) Relationship of phosphorylated alpha-synuclein and tau accumulation to Abeta deposition in the cerebral cortex of dementia with Lewy bodies. Exp Neurol 210, 409-420.

[20] Clinton LK, Blurton-Jones M, Myczek K, Trojanowski JQ, LaFerla FM (2010) Synergistic Interactions between Abeta, tau, and alpha-synuclein: Acceleration of neuropathology and cognitive decline. J Neurosci 30, 7281-7289.

[21] Abdi F, Quinn JF, Jankovic J, McIntosh M, Leverenz JB, Peskind E, Nixon R, Nutt R, Chung K, Zabetian C, Samii A, Lin M, Hattan S, Pan C, Wang Y, et al. (2006) Detection of biomarkers with a multiplex quantitative proteomic platform in cerebrospinal fluid of patients with neurodegenerative disorders. J Alzheimers Dis 9, 293-348.
[22] Perrin RJ, Craig-Schapiro R, Malone JP, Shah AR, Gilmore P, Davis Ae, Roe CM, Peskind ER, Li G, Galasko DR, Clark CM, Quinn JF, Kaye Ja, Morris JC, Holtzman DM, Townsend RR, Fagan AM (2011) Identification and validation of novel cerebrospinal fluid biomarkers for staging early Alzheimer's disease. PLoS One 6, e16032.

[23] Simonsen AH, McGuire J, Podust VN, Davies H, Minthon L, Skoog I, Andreasen N, Wallin A, Waldemar G, Blennow K (2008) Identification of a novel panel of cerebrospinal fluid biomarkers for Alzheimer's disease. Neurobiol Aging 29, 961968.

[24] Yin GN, Lee HW, Cho JY, Suk K (2009) Neuronal pentraxin receptor in cerebrospinal fluid as a potential biomarker for neurodegenerative diseases. Brain Res 1265, 158-170. 